\title{
Innovative Techniques and Technologies in
}

\section{Conservation Projects}

\author{
Andrzej Bialkiewicz \\ Faculty of Architecture, Cracow University of Technology, Krakow 30-035, Poland
}

\begin{abstract}
The present paper analyses the possibilities of using modern technology and technical engineering in conservation practices. Some examples of heritage abuse are given alongside some innovative ways of presenting relics of the past to society. Methodology consists in the scrutinizing of chosen examples, selecting conclusions and a synthetic presentation of research results. The aim is proper protection of historic architectural resources through documentation and dissemination of knowledge. First part is concerned to rejection of old aesthetics values and implementing a new one on example of Brussels' House of the People (the largest work by Victor Horta that opened on 1899 and demolished in 1965 despite a protest of architects) and ridiculous renovation in Krynica, Poland. In second part, it presents tree examples of successful implementation of innovative techniques and technologies as the Pauline fathers realizations of renovation sacred architecture (churches, cloisters), also valuable digital projects of the reconstruction of the vaults and realization of underground Museum in Krakow, Poland (the outstanding creation of the atmosphere of virtual historic reality by the latest audio-visual techniques).
\end{abstract}

Key words: Conservation, project, architecture, technology, influence.

\section{Introduction}

Ways of preserving ancient fabric in historic cities have caused heated debates which to a great extent amount to searching for a compromise between the advocates of active and passive conservation doctrine. This is because determination of the possibility or degree of creative interference in listed areas raises many doubts and so for that matter do the reliability and correctness of the interpretation of the past in the cultural context. However, many scientists see the acceptance of the present with its increasing dynamics and the simultaneous respect for the past as a symptom of our civilization's progress. This does not mean the apotheosis of innovativeness at all cost but rather the treatment of heritage with its authenticity and archeological and architectural relics as landmarks that set our direction in the world. Technical engineering and technology as such are not a threat while orthodoxy, principled criticism of any avant

Corresponding author: Andrzej Bialkiewicz, D.Sc., professor, research field: contemporary architecture. E-mail: abialkiewicz@pk.edu.pl. garde and superficiality of judgments are very much so.

Historic architecture has an important share in our cultural heritage. It is thus vital to preserve it as best we can and the task itself requires the knowledge of history, experience of and proficiency at both modern and traditional construction techniques. Needless to say, they impose a certain degree of conservativeness on our actions suggesting reference to older construction methods and building materials. Consequently, the ruling principle once was to save historic objects using traditional methods so as to make them best reflect the past times with their aesthetic concepts, tastes, technologies, social relations and cultural connotations. More often than not, the greatest value of a monument lay in its authenticity and originality, lack of any signs of rebuilding, adaptation or changes. This passive protection still has many adherents.

However, the pace of advancements in architectural design and performance combined with increasing dependence on structural engineering ideas often 
influence conservation design with regard to materials and technology as well as structure and function. This brings us to active conservation whose supporters often promote free creation and do not view the historic object with its cultural, historic and spatial context as an unnecessary burden of the past.

\section{Brussels' House of the People}

Doubts are raised about the legitimacy of both approaches to conservation. Disputes continue among conservators and it will probably take a long time before they are settled. An important issue at this point is the rapid progress of technicalization, digitalization, industrialization and urbanization of many countries. It influences the creation of new architecture and also the methods of preservation of the built heritage. Innovativeness permeates design and construction practice. New materials and technologies serve experimental engineering solutions to meet the growing needs of the society. Therefore, the dichotomous approach to relics of the past amounts more and more often to very subjective and non-conventional ways in which designers read the signs left by the times and men.

The past of architecture is not always obvious. Its history concerns various events, circumstances, inventions and fashions. Even its dilapidation and neglect have various shades. Mostly, the reason for architectural transition is rejection of its aesthetics. It so happened in history that a predominant style came vehemently into fashion only to be soon annihilated by man. At this point, it is worth reflecting on the speed and scale of the transformations that take place; what used to be a bold, avant-garde engineering solution after merely 66 years became a derelict object, unattractive for investors and worth only of demolishing. It seems that the pace of technological progress results in rapid decapitalization of built objects and what is new quickly becomes obsolete and devoid of currently appreciated values.

This is what happened to Brussels' House of the
People, the largest work by Victor Horta that opened on April 2, 1899. Despite the irregular shape of the lot adjacent to the circular Vandervelde-Plein square the architect managed to create a very functional building. It housed offices, cafes, shops, conference halls and a ballroom (Fig. 1).

The facade was mostly white iron of which 600,000 $\mathrm{kg}$ were used for the construction. The construction works lasted 18 months. Its utility area totaled 8,500 $\mathrm{m}^{2}$. Soon after completion, in 1899 , it was acclaimed a masterpiece and an example of modern architecture due mainly to the pioneering combination of steel and brick. The building was demolished in 1965 despite a protest of architects. Later on, attempts were made to reconstruct the object but the disassembled elements were numbered and stored in a shed in Teuven for the following 20 years. In 1980, a decision was made to create Park King Baudouin in Jette where the fragments of House of the People were transported. However, they were not protected and when the funds ran out, the project fell through and Horta's masterpiece rusted away and some of it was sold off as scrap metal. Since 1966, the place of House of the

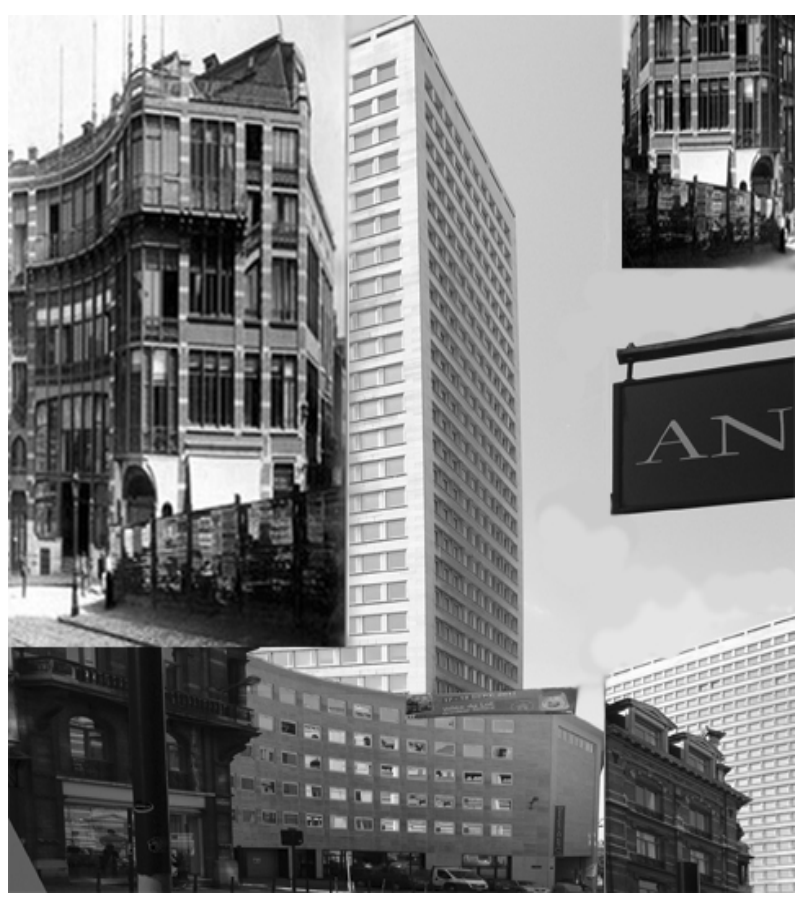

Fig. 1 House of the People, Brussels, Viktor Horta, 1899 versus Blaton Tower, 1966. 
People on the Vandervelde-Plein square has been occupied by office building called Blaton Tower. This way of exchanging urban fabric was quite radical even by Brussels' standards. The city is also famous for leaving only the front walls of historic tenement houses and demolishing the rest to make room for tall buildings.

\section{Modernizations}

Old tenement houses still prevail in European cities and are not always admired. Their archaic form and antiquated appearance cause resentment and disapproval while the prices of lots in the centers of cities soar. Therefore, actions are taken to modernize them by making reference to the latest material and structural solutions so that they can regain social approval. The most rewarding material in this respect seems to be glass which embodies the latest technologies. Actions of this kind are not rare or restricted to specific sites or cities. Peculiar creations can be found throughout Europe from Lisbon in Portugal to Krynica in Poland (Fig. 2). In the former, admiration for innovative technologies is manifested in the form of downright ridiculous additions of glass top floors to old tenements. In the latter, the house has been cased with glass walls while the historic regional roof and rich details are reflected in the walls like in a mirror. One cannot but wonder if such an attitude to the inevitable passage of time, affirmation of innovativeness and trite interpretation of the past, particularly as regards reading its signs, is a marginal phenomenon or a clumsy way of demonstrating modernity.

\section{The Pauline Fathers Realizations}

Historic objects of architecture often continue to be used as places of residence or work. It involves the necessity to adapt them to meet the current needs which means introducing new facilities into the existing structures so that they can perform new functions. New technologies and materials become a

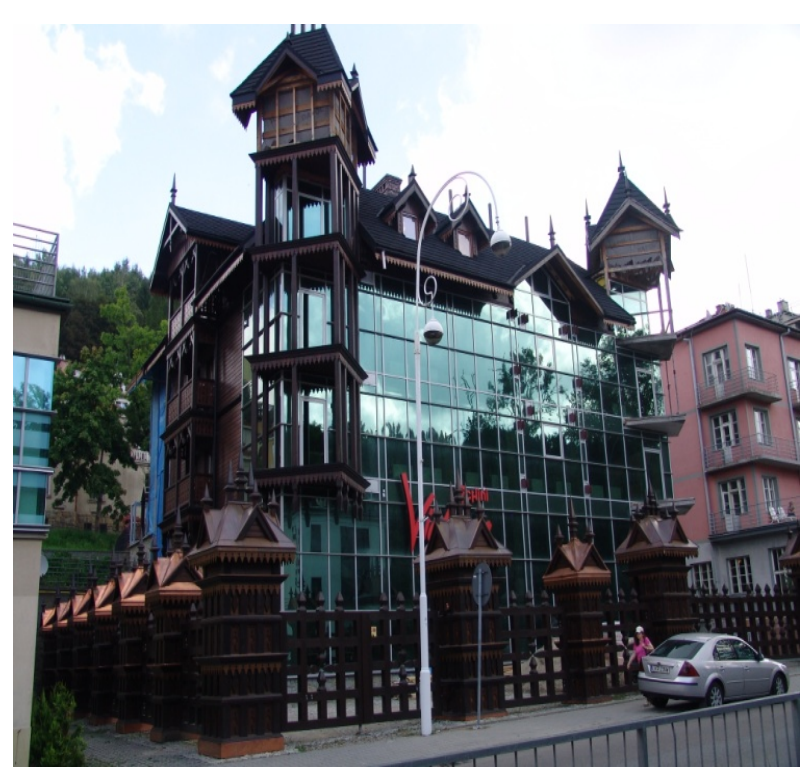

Fig. 2 Modernization through material transformations, Krynica, Poland.

must in conservation practices. They help preserve and maintain the object. They are often hidden under layers of plaster and yet necessary to ensure the good condition of the ancient structures that weakened with time. During their lifetime, the buildings have gone through all sorts of refurbishing and rebuilding processes. The works were often extemporaneous and aimed at adapting the building to the changing needs. More often than not, historic values were of little concern. Preserving historic form of the objects with their stylistic layers requires removal of all the haphazard additions. Former structural and architectural details are restored. The buildings are often damp. New non-invasive conservation techniques help to solve this problem. Renovating plaster is often used wide-pore and salt-inhibiting. The external walls of the buildings are thick making the thermal conductivity coefficient meet contemporary requirements.

Sacred architecture draws particular attention of art historians and common people. Churches erected in various epochs are permanent part of cultural heritage. Their architecture distinguishes the localities where they stand while its aesthetic values and prestige make us aware of their nobleness. Sacred buildings are determined to a large extent basic trends in the history 
of architecture. The range of their influence and persistence of form allow them to be seen as a synthesis of tradition and modernity [1-6]. Some sacred objects are clearly distinct from others and owe their characteristic features to the investors, e.g., the Pauline Fathers. Their realizations are very interesting and to recipients' taste. The Pauline Fathers treat their religious mission with care and this approach let the order live for centuries. The general of the order of Saint Paul wrote: The fact that the order has existed for so long gives genuine satisfaction and yet the future based on such foundations makes us aware of great responsibility. At such moments we resort to the spiritual and cultural heritage of the order. It has left a significant stamp on the history of the church in Eastern Europe, particularly in the history of Hungary and Poland ..., the contribution of the Pauline Fathers to Polish history and culture is undeniable and impossible to be overrated [3]. It should be mentioned that the generals, provincials and priors of the order have always employed the best Polish and foreign architects and artists to create objects of the highest value and lasting function. Nowadays, the objects are transformed with the help of the latest techniques and technologies to make sure that the ancient walls contain within them absolutely modern life.

The function which is characteristic of Pauline buildings has not changed significantly even though it has been slightly altered. For nearly 400 years, the architectural forms have been adapted to the changing needs of their users. This seems to be the reason why the architecture continues to survive since, on the one hand, it is constantly modernized and, on the other, its form is meticulously conserved. New techniques and technologies are applied not only to preserve the objects in their physical form but also to maintain their identity and climate. Thus the ideals that were the driving force of the Paulines' actions in the Middle Ages and modern times still apply. In the buildings which allow continuation and where the spirit of modern times makes it necessary, we see it happen. In the objects, where the past seems to be irrevocably closed, research is carried out to preserve the memory of the past achievements. It is owing to the trends of Pauline science and culture that the renowned monasteries of the "white monks" have not become only lifeless museums of old art and culture [3].

\section{The Vaults and Its Reconstructions}

Many buildings which were several centuries old suffered destruction due to disasters and wars. They turned into ruins which were restored to their original shape because of their emotional, aesthetic, historic and cultural value. Although more than 50 years have passed since the end of World War II, there still remains the problem of restoration of the Gothic vaults in numerous churches, e.g., in Gdansk, Poland.

The vaults which were built five centuries ago still adorn the churches of Gdansk. Some of them have stayed intact, others have been replaced with reconstructions since they were destroyed in the war. Attempts have been made to recreate the original drawings and their layout. Unfortunately, the sculptures and paintings have been lost which impairs the aesthetic quality of the interior. Nowadays, the dominant feature is white plastered reinforced concrete vault areas with brick ribs. They still impress with the beauty and logic of their structure and the variety of composition but their structural authenticity is minimal.

While researching the history, Kulig [7] reached for an almost forgotten work by Ranisch, entitled Beschreibung aller Kirchen-Gabaude der Stadt Dantzig [8], which is Poland's oldest and extremely valuable source of knowledge about the construction of vaults in medieval times. It is a 17 th century treatise written by a builder, architect and researcher fascinated by Gothic masterpieces. Several copies of the treatise edited in 1695 in Gdansk have been preserved. Luckily, which is a significant factor for comparative studies, many objects described in the treatise have survived. The old print has rarely been 
used as a research source despite its great cognitive and documentary value. The forgotten work was used after 300 years as an invaluable and still relevant document to help restore the historic architecture of Gdansk and, in particular, the churches with medieval vaults that were destroyed in World War II. The architects who designed the reconstruction of several vaults depended on Ranisch's drawings but did not read his treatise or follow his directions. A thorough analysis of his text let the author reinterpret Ranisch's construction principles and develop a universal geometric method of vault restoration. An analysis of the historic treatise made it possible to study the building methods of old masters, their ability to plan harmonious divisions of space and to make synthetic records of building structures which, translated into the digital language, allows the creation of virtual interiors of Gothic churches and, in this way, the restoration of their medieval originals. Such virtual images are extremely helpful for architects in their work since they let them go back in time and watch past epochs. They serve both knowledge and culture.

The studies resulted in the Malbork castle vault restoration project (Fig. 3). The concept of the restoration of the castle church vault appeared in connection with the resumed conservation works. The conservation and restoration works in the Malbork castle have continued for over 200 years.

The concept is consistent with the basic function of the whole castle as a museum and also with the idea to let the church resume its sacred function it had performer for seven centuries. The castle church suffered significant damage during World War II and the restoration of its interior and vaults is still under way.

The dominant feature of the church are the starry vaults established here as a novelty in the 14th century, probably for the first time in Prussia, which spread throughout Pomerania and became common in many object in the region. The restoration concept is based on historic sources and assumes faithful recreation of the starry vault structure.

In Ref. [9], Anna Kulig makes reference to a Gothic church in Szydlowiec (near Radom) (Fig. 4). St. Sigismund church is a 15th century stone structure with a traditional layout featuring a wide nave with side chapels and a lower and narrower presbytery. An exceptional element is a huge $(13 \mathrm{~m} \times 8.5 \mathrm{~m})$ full-size
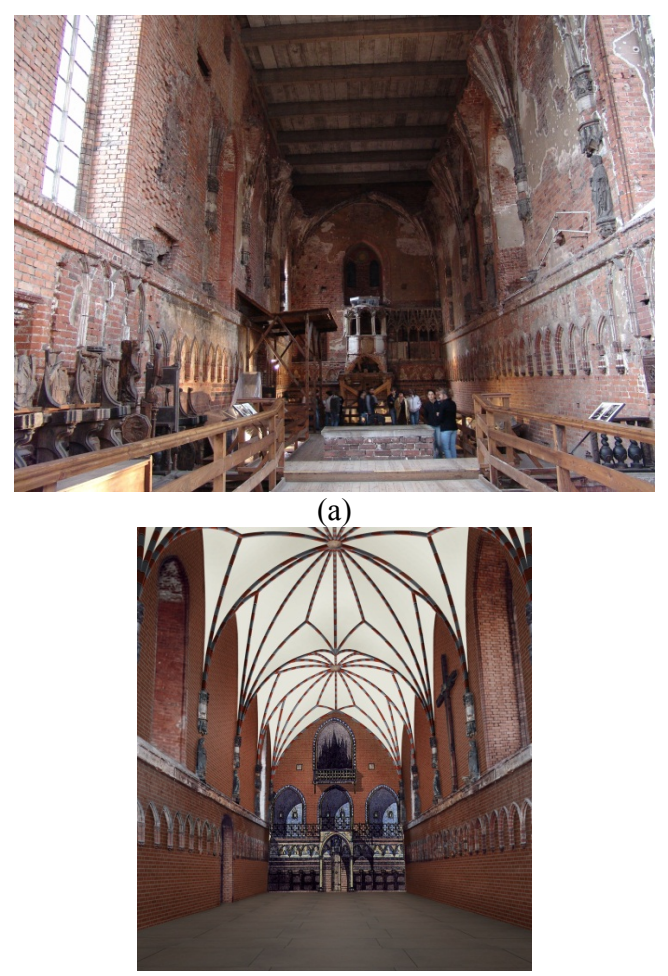

(b)

Fig. 3 The Malbork castle vault reconstruction design: (a) the current state; (b) project of the reconstruction.

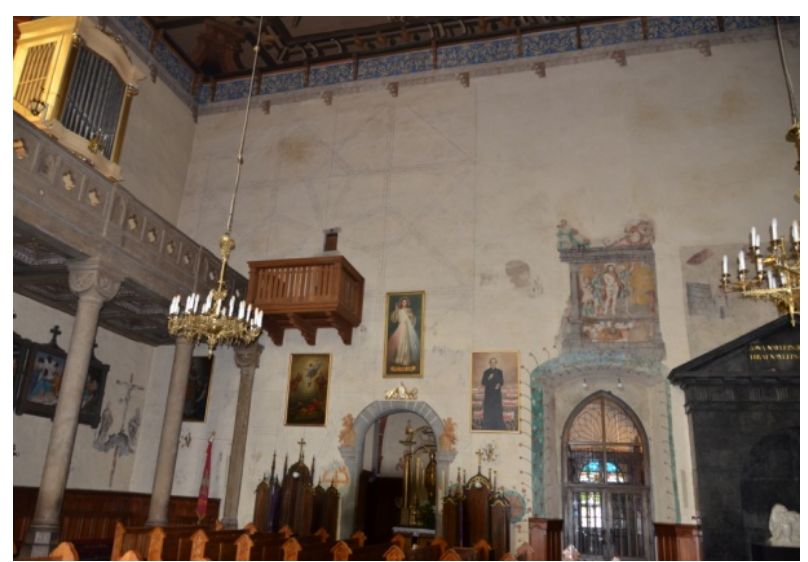

Fig. 4 Interior of the Gothic church of St Sigismund in Szydlowiec, Poland. Nave interior. View of the northern wall with the engraved drawing from the turn of the 15th and 16th centuries. 
plan of the vault drawn by the Gothic architect and uncovered in 20th century. It was carved in plaster and the $2 \mathrm{~mm}$ grooves were filled with grey paint to make them more visible.

Basing on the medieval plans, Kulig has created a visualization of the object. In this way, visualization of historic architecture extends the scope of research and documentation. The visualization of the Szydlowiec drawing made possible recreation of vaulted space. Computer rendering of the metric relations within the monument adds to and updates the material resources available to the society (Fig. 5). It can also be further modified and used for other purposes such as digitally made physical models. For conservationists of historic objects, visualization is a valuable form of presenting modernization projects, arrangements of interiors or the surroundings of the object. It can also become an attractive illustration because of the moving images. Making a digital geometric model of a historic object is time consuming while graphic design offers almost instant and attractive option of observation and illumination.

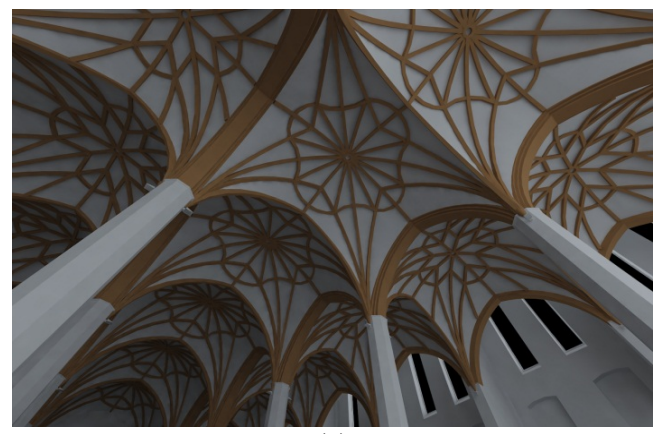

(a)

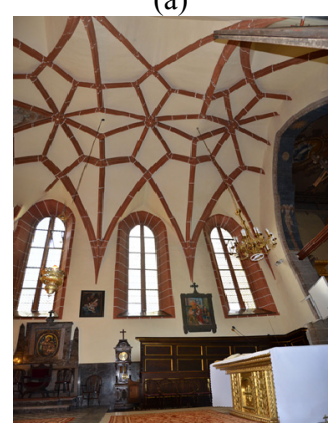

(b)

Fig. 5 The Szydlowiec vault reconstruction project. Virtual stellar network vault: (a) vaults; (b) fragment of the interior.

\section{The Underground Museum in Krakow}

The latest audio-visual techniques and the atmosphere of virtual reality of the historic past have recently become key features of museums. The formula of exhibiting relics of the past has clearly changed. The role of the establishments as creators of culture has prevailed over their purely scientific and documentary aims. The multimedia and "mapping" which is a technique bringing objects to life have become fashionable and attractive. For many years, underground exhibitions have been staged in the spaces which are authentic witnesses of the historic past and their viewing is improved by the use of modern technology. Roman catacombs, the underground Louvre museum, the remains of Santa Reparata, an early Christian basilica discovered beneath the Santa Maria del Fiore cathedral in Florence [10] or the Roman Forum in Saragossa near Pilar Plaza and beneath the La Seo cathedral are just a few examples. Recently, the 19th century Acropolis Museum has been extended. It is an excellent example of a contemporary museum which makes use of all the multimedia installations. The authors of the Caracorum Museum near Viena have gone even further and, apart from using the sophisticated technology, have reconstructed the thermae. There are many press reports about the excellent interactive museum at Herculanum, south of Naples, which has caused a significant decrease in the attendance rate at the original ruins of the city.

In 2010, visitors were admitted to an exhibition under Krakow Market Square. The exhibition of medieval Krakow was organized by the Historical Museum of the city (Fig. 6). The multimedia technique has filled the underground spaces with the hustle and bustle of everyday life of a medieval town and holds many visual surprises for the visitors. The main exhibition hall is entered through a curtain of water vapour on which animated scenes from the everyday life in the Middle Ages are projected. For a moment, one can feel as if at a medieval market place. 


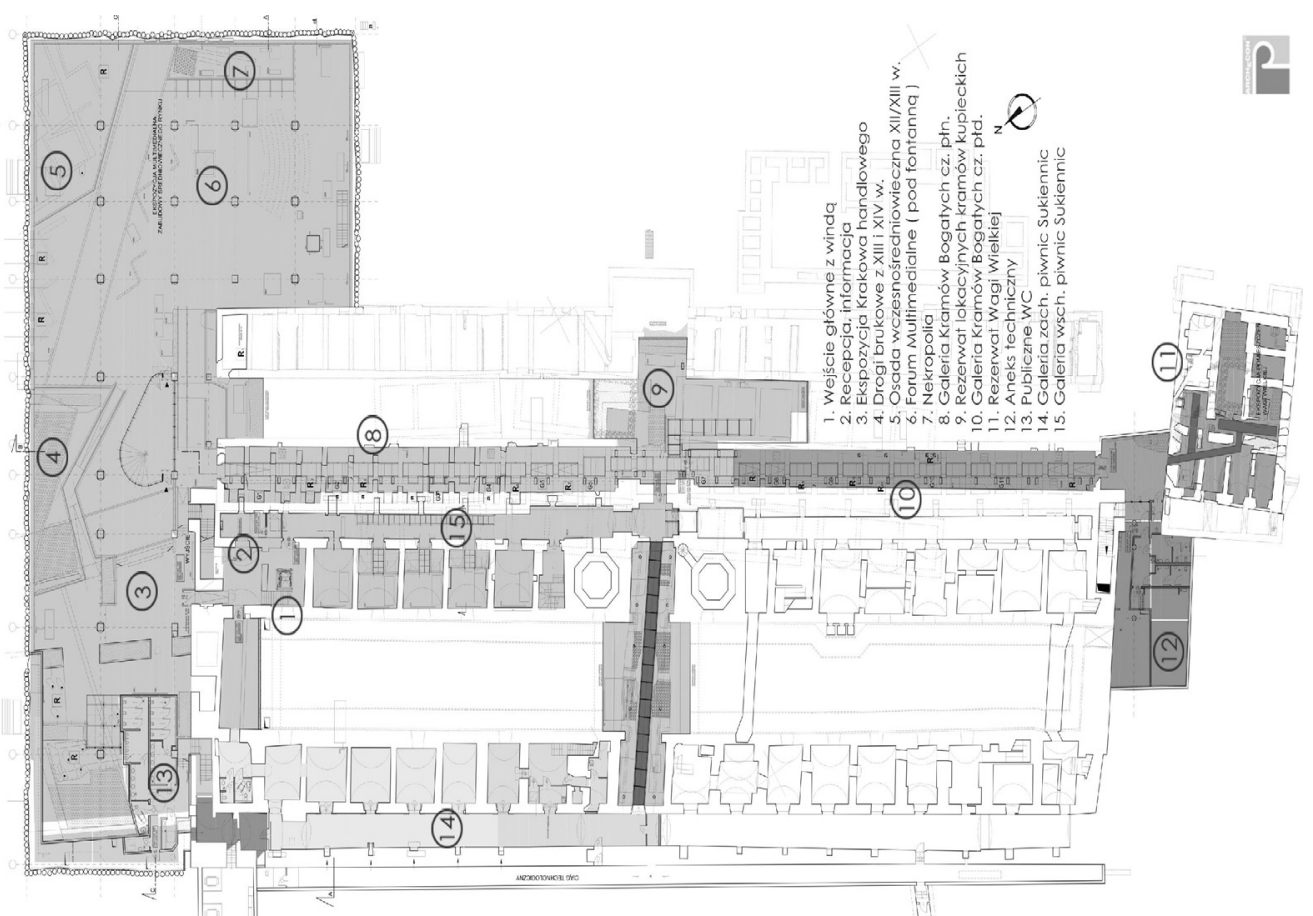

Fig. 6 Plan of the museum under the Market Square, Krakow 2010 (1. Main entrance with a lift; 2. Reception area, enquiries; 3. Exhibition of trade in Krakow; 4. 13th and 14th century cobblestone roads; 5. Early medieval settlement; 6. Multimedia Forum (under the fountain); 7. Necropolis; 8. Rich Stalls gallery-northern part; 9. Merchant stalls reserve; 10. Rich Stalls gallery—southern part; 11. The Great Scales reserve; 12. Utility space; 13. Toilets; 14. The Cloth Hall cellars gallery-western part; 15. The Cloth Hall cellars gallery-eastern part).

Owing to the holograms, stalls with stacks of goods are at arm's reach, a woman carries a basket brimming with fruits, a man who looks like a pickpocket tries to get at the purse of a rich man passing by. A preacher at the background urges all to do penance. Further inside the museum 3D architectural images are projected. Visitors can go around them and see illusory roads that go on for miles [11].

The author of the visionary concept of the museum is Kadluczka [12-14], an architect, conservator, professor of the Faculty of Architecture at the Cracow University of Technology. His penchant for unconventional, avant-garde and innovative solutions allowed a perfect design of the museum spaces. According to him, "it is a fundamental issue for everybody including our generation of creators of another cultural layer for which we need to determine a definite framework and make sure that the heritage of the past is not a barrier but a driving force of our civilization development" [15].
The archeological excavations that were carried out here from 2004 to 2006 resulted in many unexpected discoveries (Fig. 7). Half way between the Cloth Hall and the Adam Mickiewicz monument there surfaced the walls of Kramy Bogate (the Rich Stalls) where luxury goods were sold 700 years ago. Near St. Adalbert's church, the foundations of Wielka Waga (the Grand Scales) building were found. In the Middle Ages, it was really one of the biggest pairs of scales in Europe, as the name suggests. It was used for weighing mainly lead and copper. Archeologists found the remains of a settlement which had existed here before it was called Krakow. The architectural interior of the Underground Museum was finally defined by the area and location of particular relics and the modular network of the pillars supporting the plate of the square but its artistic shape and atmosphere were conceived as a "universe" with blurred boundaries in the middle of which there appear exhibition artifacts in the form of authentic 
medieval architecture supplemented with archeological utility objects illuminated with bright light and accompanied by a high-tech system of multimedia information [15] (Fig. 8).

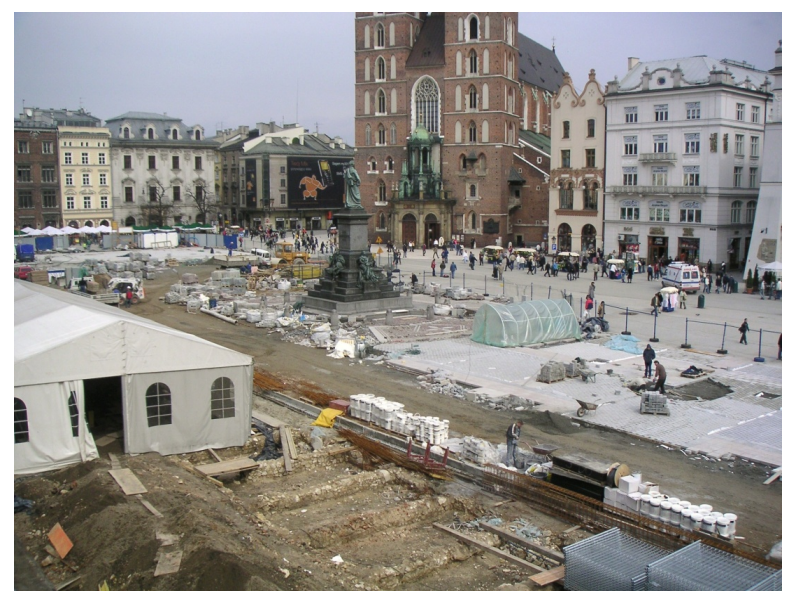

Fig. 7 Construction of the museum under the Market Square, Krakow, 2010.

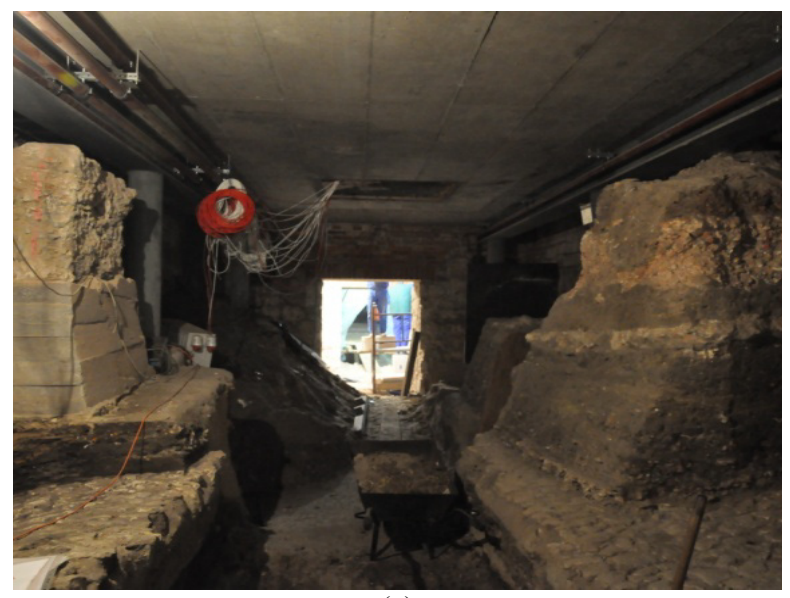

(a)

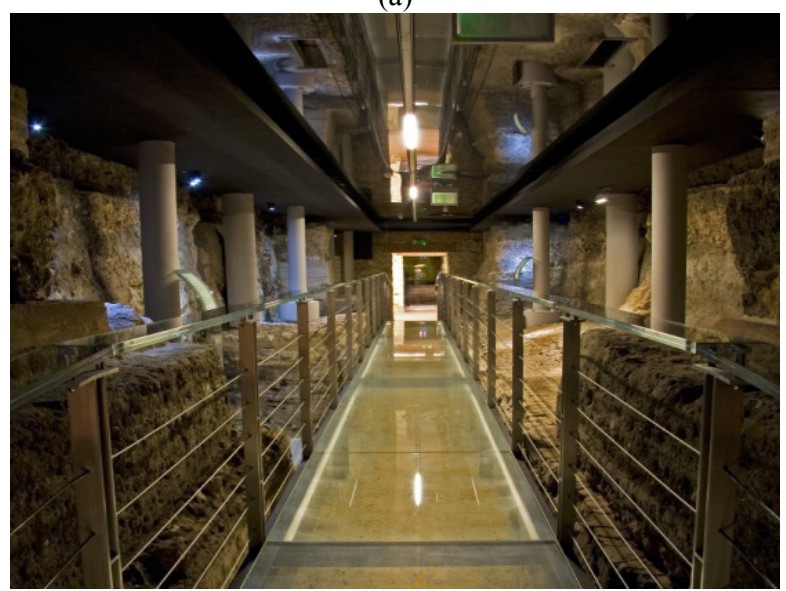

(b)

Fig. 8 Medieval Krakow exhibition under the Market Square 2010: (a) before renovation; (b) after renovation.
The museum consists of a large hall with three parallel corridors. The longest one features the Kramy Bogate (Rich Stalls). They are situated next to the Cloth Hall which in the Middle Ages comprised two rows of buildings with a street between them. They do not correspond exactly to the present footprint of the building. Completely new museum facilities has a total of $6,000 \mathrm{~m}^{2}$ including the corridors. Glass floors, footbridges and platforms will give a view of wooden farmsteads, houses, stalls and waterworks restored on the basis of archeological findings.

In order to achieve the effect of blurred boundaries within the exhibition, the design solutions include dark grey and black floors, glass railings for the ramps and exhibition paths, auburn-black cladding of support pillars, dark grey elements to complete architectural objects, a "barrisol" stretch ceiling with a reflective surface and glass platforms suspended over the relics to allow the visitors direct perception. The key factor of the exhibition is light which brings out the most important fragments of old built environment of the square, its municipal facilities and the necropolis from the times before the foundation of the city with models of graves and burials. The multimedia, lasers and computer models of the exhibits are unobtrusive but indispensable parts of the exhibition [3].

\section{Conclusions}

It must be noted that access to the unique collection of nearly 900 underground artifacts dating back to the 11 th through 14 th century was made possible owing to modern technology, all the techniques available and with the use of a whole range of innovative methods of arranging the layout of museum spaces. The result is a new value as regards current conservation project implementation in that technological and technical innovativeness supported both the exhibition and preservation of precious cultural heritage.

Thus innovative engineering ideas determine the current pace of architectural conservation design in 
the areas of technology, materials and function. Fabulous museum exhibitions lead visitors into a virtual world which is a perfect semblance of the reality.

While designing, one can almost touch the perfect but illusory vaults, interiors or whole spaces. These visions appear owing to the supporters of active conservation and free creation who do not see the historic object with its cultural, historic, or spatial context as an unnecessary burden of the past.

\section{References}

[1] A. Bialkiewicz, Old architecture today, Czasopismo Techniczne (Technical Journal) 15 (107) (2010) 33-42. (in Polish)

[2] A. Bialkiewicz, Duration, passing and a function, Czasopismo Techniczne (Technical Journal) 14 (108) (2011) 65-74. (in Polish)

[3] A. Bialkiewicz, The role and influence of Pauline architecture on nom-architects, Architectus 2 (28) (2011) 4-21.

[4] J. Golonka, J. Zmudzinski, Cultural and artistic patronage of the Pauline Polish, in: Jubilee of the 700th Anniversary of the Pauline Order, Czestochowa, 2008. (in Polish)

[5] J. Rabiej, Tradition and Modernity in Architecture of Catholic Churches, Temple as a Cultural Phenomenon, Gliwice, 2004. (in Polish)

[6] M.J. Zychowska, Saved phenomenon, Technical Journal 14 (108) (2011) 407-414. (in Polish)
[7] A. Kulig, The geometrical methods in the reconstruction of the Gothic vaults based on the selected sacred interiors rebuilt in Poland after World War II, Ph.D. Thesis, Cracow University of Technology, Krakow, 2006. (in Polish)

[8] B. Ranisch, Description of All the Churches of the City-Building Dantzig, Dantzig, 1695. (in German)

[9] A. Kulig, About Gothic architectural drawing - Based on the discovered sources in Szydłowiec, Visualization based on medieval monument in the plans, in: The Third Forum Architecturae Poloniae Medievalis, Cracow University of Technology, Wydawnictwo, Krakow, 2013, pp. 157-167. (in Polish)

[10] F.K.B. Toker, Florence cathedral: The design stage, The Art Bulletin 60 (2) (1978) 214-231.

[11] Following the Tracers of European Identity of Krakow [Online], Rynek Underground Permanent Exhibition, http://www. podziemiarynku.com (accessed Jan. 31, 2014).

[12] A. Kadluczka, Orthodox creation of architectonic space in the underground museum of the market square in Krakow, Wiadomości Konserwatorskie Stowarzyszenia Konserwatorów Zabytkow 28 (2010) 9-17.

[13] A. Kadluczka, Underground museum in Krakow's main market square, Cracow University of Technology, Kraków, 2010. (in Polish)

[14] A. Kadłuczka, The main market square in Krakow, the underground museum and the cloth hall, Republic of Poland, the Polish Institute, Rome, Krakow, 2011.

[15] D. Hajok, Fascinating Krakow Eight Meters under the Market, Gazeta Wyborcza, Sep. 3, 2010, http://wyborcza. p1/1,76842,8333069,Fascynujacy_Krakow_osiem_metro w_pod_Rynkiem.html\#ixzz25gY9j2kt (accessed Jan. 1, 2014). (in Polish) 